NBER WORKING PAPER SERIES

\title{
DOES ORGANIZATIONAL FORM DRIVE COMPETITION? EVIDENCE FROM COFFEE RETAILING
}

\author{
Brian Adams \\ Joshua Gans \\ Richard Hayes \\ Ryan Lampe \\ Working Paper 22548 \\ http://www.nber.org/papers/w22548 \\ NATIONAL BUREAU OF ECONOMIC RESEARCH \\ 1050 Massachusetts Avenue \\ Cambridge, MA 02138 \\ August 2016
}

We wish to thank Chamath De Silva, Kimberly Jin, Alexandra Knight, Nicholas Kozeniauskas, Rachael Meager, Nguyen Nguyen, and Suphanit Piyapromdee for research assistance. Thanks to John Asker, Avi Goldfarb, Heski Bar Isaac, Mara Lederman, and Joel Waldfogel for helpful discussions. Special thanks to Eric Fischer for providing data on Flickr photo uploads. All errors are our own. Lampe acknowledges research support from DePaul University. All views expressed in this paper are those of the authors and do not necessarily reflect the views or policies of the U.S. Bureau of Labor Statistics, the Australian Competition and Consumer Commission, or the National Bureau of Economic Research.

At least one co-author has disclosed a financial relationship of potential relevance for this research. Further information is available online at http://www.nber.org/papers/w22548.ack

NBER working papers are circulated for discussion and comment purposes. They have not been peer-reviewed or been subject to the review by the NBER Board of Directors that accompanies official NBER publications.

(C) 2016 by Brian Adams, Joshua Gans, Richard Hayes, and Ryan Lampe. All rights reserved. Short sections of text, not to exceed two paragraphs, may be quoted without explicit permission provided that full credit, including $(\odot$ notice, is given to the source. 
Does Organizational Form Drive Competition? Evidence from Coffee Retailing

Brian Adams, Joshua Gans, Richard Hayes, and Ryan Lampe

NBER Working Paper No. 22548

August 2016

JEL No. L11,L15

\begin{abstract}
This article examines patterns of entry and exit in a relatively homogeneous product market to investigate the impact of entry on incumbent firms and market structure. In particular, we are interested in whether the organizational form of entrants matters for the competitive decisions of incumbents. We assess the impact of chain stores on independent retailers in the Melbourne coffee market using annual data on the location and entry status of 4,768 coffee retailers between 1991 and 2010. The long panel enables us to include market fixed effects to address the endogeneity of store locations. Logit regressions indicate that chain stores have no discernible effect on the exit or entry decisions of independent stores. However, each additional chain store increases the probability of another chain store exiting by 2.5 percentage points, and each additional independent cafe increases the probability of another independent cafe exiting by 0.5 percent. These findings imply that neighboring independents and chains operate almost as though they are in separate markets. We offer additional analysis suggesting consumer information as a cause of this differentiation.

Brian Adams

Bureau of Labor Statistics

Washington, DC

adams.brian@bls.gov

Joshua Gans

Rotman School of Management

University of Toronto

105 St. George Street

Toronto ON M5S 3E6

CANADA

and NBER

joshua.gans@gmail.com

Richard Hayes

Australian Competition and Consumer Commission Melbourne VIC 3000

richardhayes100@gmail.com

Ryan Lampe

California State University, East Bay

ryan.lampe@csueastbay.edu
\end{abstract}




\section{Introduction}

Textbook models of competition suggest that product differentiation mediates competitive pressures. Sources of product differentiation can include location, matching to specific tastes, or quality differences. However, in some markets we also see competition between distinct organizational forms. In retailing, for instance, the competition arising from chains (which operate multiple outlets in different locations) on independents (which have a single outlet in a single location) has been of intense interest. Part of this comes from issues arising from economies of scale (with so-called Big Box retailers providing services of numerous independent outlets over a range of products in a local area). But in other situations, chains are distinctive mainly by their being a chain rather than being a fundamentally distinct local retail structure. Here we have in mind food chains such as McDonalds or Starbucks that provide outlets of a similar scale and with a similar selection of products to independents. Assessed at the level of competition in a locality, the chain status does not, at first glance, offer a distinctive form of product differentiation. Instead, it offers more nebulous concepts such as brand, reputation, and consistency of service.

From a theoretical perspective, a solid prediction in such environments is that the entry of a chain outlet into a local market will impose competitive pressure on independents and, in some cases, precipitate their exit. Of course, chains will consider local market characteristics, such as market size or density of consumers when deciding where to enter, and, thus, exit may not be observed in response to entry if the market was selected precisely because it was large or growing. In addition, some urban economics models suggest that entry can facilitate the movement of consumers to a location as they can be assured of sufficient competition once they arrive there (e.g., Krugman, 1991). Thus, entry could lead to agglomeration externalities which reduce exit hazards rather than increasing them.

To test this somewhat fundamental notion regarding competition, we have assembled a unique dataset of entry and exit decisions by coffee retailers over two decades, from 1991 to 2010. Our data identifies the exact location and years of operation for 4,768 cafes and coffee shops in Greater Melbourne, Australia. We can determine whether these retailers were independent or part of a chain. We then analyze the impact of each type of retailer on the entry and exit patterns of nearby competitors. Because firms choose their locations based on market size, entry probabilities will be biased upward if adequate controls for location characteristics are not included. We address this endogeneity concern by including geographic market fixed effects, which is possible given our long 
panel. Demographic data on household income, population, and unemployment allow us to control for time-varying changes in market characteristics.

The Melbourne coffee retail market presents an appealing case study to analyze competition between chains and independents for several reasons. First, as price dispersion between coffee retailers is small, they compete on the basis of location for which rich geographic location data is available. Second, coffee is a culturally important product, which is evidenced by the protests and hostility from local residents when chains such as Starbucks attempt to enter their community (Clark, 2008). Third, the beginning of our sample predates the entry of coffee chains into Melbourne so there is variation in the number and existence of chains. Fourth, there is less heterogeneity in output for coffee retailers and cafes (food, coffee, and other beverages) than for large retailers like Wal-mart, which sell a very wide variety of products. This makes the definition of a local market more precise for coffee retailers.

As described in Section 2, our data include the location, entry and exit years of 4,196 independent cafes, 151 independent coffee retailers, and 421 chain stores between 1991 and 2010. The largest chains in our sample include Gloria Jean's Coffee (an Australian-owned chain), Hudson's Coffee (owned by the Dubai-based Emirates Group), and Starbuck's Coffee (based in the United States). Coffee shops and cafes are partitioned into 300 local markets, based on census regions, with separate markets for 11 large suburban shopping centres.

Section 3 presents our model and estimation strategy while Section 4 presents our main findings. We find that chain coffee retailers do not appear to drive existing independent cafes out of the market. Each additional chain store in a neighborhood market is associated with an increase in the annual exit probability of an independent cafe by an average of only 0.05 percentage points. Each independent retailer is associated with an increase in the exit probability of competing independent retailers by an average of 0.55 percentage points and each chain outlet is associated with an increase in the exit probability of other chain outlets in its market by 2.46 percentage points. We also find that the presence of chains also deters entry of additional chain outlets more than it deters entry of independents. For each additional chain store, the probability of entry by a new independent cafe decreases by 1.3 percentage points, but the probability of entry by additional chain stores decreases by 7.0 percentage points.

To address the concern that our demographic data do not adequately control for time-varying characteristics, we re-estimate our baseline exit equation with separate market fixed effects for every five-year interval. Our main finding is unchanged: chain store entry continues to exhibit no 
significant effect on the likelihood of independent cafes exiting.

The estimated entry and exit probabilities are therefore consistent with any entry and exit model in which chain and independents have a negligible effect on each other. This point renders a structural analysis unnecessary. In other settings, a structural analysis would allow one to compute the counterfactual number of independent retailers in a market in the absence of chain stores. However, in our setting, the number of independent coffee retailers is unaffected by the presence of chain stores so the equilibrium number of independent cafes will be largely unchanged. We therefore favor our reduced form approach, which offers a more transparent strategy for identifying the impact of chain store entry on the exit probabilities of independent stores. Nevertheless, because there is little interaction between chains and independents, the logit estimates of our baseline specification also approximate the policy functions of a more sophisticated discrete time dynamic equilibrium model of entry and exit, which we show in Section 3.

These results suggest that independents and chains operate in what might be considered separate markets. In antitrust analysis, economists often look to demand-side substitution between products to determine market definition, i.e. what firms are direct competitors in a market. Our results here suggest that an independent coffee retailer and a chain may not be direct competitors. While we do not examine price competition, our approach takes a longer-term perspective in terms of entry and exit decisions. Thus, independent entry precipitates independent exit but not chain exit while chain entry has the opposite effect. This suggests that, at the customer level, despite the seeming similarity in products sold, demand-side substitution is contingent on organizational form.

Based on this, we examine more carefully the locus of competition. One hypothesis is that consumer information drives these choices. For instance, it may be that independent coffee retailers are preferred by knowledgeable consumers while chains are preferred by those without local knowledge. Using a variety of measures to identify areas where the mix of consumer types might vary, we find some support for this mechanism. In addition, we find that independent entry tends to precipitate exit from young rather than older independent firms. As it is possible that consumers are less knowledgeable regarding younger firms, these findings on the locus of competition are consistent with our main hypothesis that consumer knowledge plays an important role in these entry and exit patterns.

The remainder of this article is structured as follows. In the next section we describe the Greater Melbourne market for coffee and our data. In Section 3 we derive our model of entry and exit. Section 4 presents our results, and a final section concludes. 


\section{Industry overview and data description}

\subsection{Industry description}

We analyze the entry and exit decisions of coffee retailers in the Greater Melbourne Area of Victoria, Australia. ${ }^{1}$ Australia has a mature coffee industry and culture, which is a by-product of Greek and Italian immigration beginning after World War II (Patterson, Scott, and Uncles, 2010). Between 1939 and 2007, Australia's annual coffee intake increased from $0.3 \mathrm{~kg}$ to $2.4 \mathrm{~kg}$ per person, and industry sales currently exceed $\$ 4$ billion (Jellie, 2007; Gargano, 2014). ${ }^{2}$ Victoria's share of industry revenue in Australia grew during the past decade, and the state represented almost 30 percent of Australian coffee establishments in 2014. New South Wales, which includes Sydney, represented approximately 35 percent of establishments (Gargano, 2014, p. 17).

The Greater Melbourne market for coffee is an appealing case study to investigate the impact of chain stores for several reasons. First, Melbourne's European-style cafes compete primarily on the basis of location, meaning the absence of price data is less significant than it is in other industries such as discount retailing. Competition has not centered on price because coffee is relatively cheap and there is little price dispersion among stores (Gargano, 2014, p. 20). ${ }^{3}$ Barriers to entry are low because start-up costs are small (machinery can even be leased) and no formal qualifications are required. Second, coffee is a culturally significant product, and Australians are discerning coffee drinkers (Patterson, Scott, and Uncles, 2010). Therefore, in addition to location, Melbourne's cafes also compete on the quality of their coffee (including the range of choices, e.g. latte, cappuccino, and flat white) and the ambiance of their establishment. An association between better quality coffee and atmosphere with independently owned establishments is one potential explanation for the dominance of independent coffee shops.

Third, the beginning of our sample largely predates the entry of coffee chains into Melbourne so there is variation in the number and existence of chains. Several different chain stores operate in the Greater Melbourne Area but no company owns more than 6 percent of establishments. In our sample, the most prominent chains are Gloria Jean's Coffee (a total of 79 stores across the sample timeframe), McCafe (housed in 118 McDonald's stores), Hudson's Coffee (30 stores), The Coffee Club (22 stores), and Starbuck's Coffee (25 stores). The first chain to enter was Brunetti

\footnotetext{
${ }^{1}$ We do not consider restaurants, and takeaway food services that do not primarily compete in the market for coffee.

${ }^{2}$ All amounts are in nominal Australian dollars.

${ }^{3}$ Prices of an espresso coffee in 2008 at six chain stores across Australia (Gloria Jean's, McCafe, Coffee Club, Wild Bean Cafe, Hudson's, and Starbucks) ranged from $\$ 3.10$ to $\$ 3.60$ (Patterson, Scott, and Uncles, 2010).
} 
in 1985, though a second Brunetti location was not opened until 1999. By 1991 there were seven chain locations (one BB's Cafe, two Bonbons Bakeries, one Brunetti, and three Muffin Breaks). Starbucks first entered the Australian market for coffee in 2000 but closed most of its stores by 2008, including 17 of its then 22 Melbourne stores. Chain stores often locate in shopping malls and suburban shopping centers where foot traffic is larger and the importance of quality is potentially lower (Gargano, 2014, p. 9). Data on store locations reveal that 81 of 421 (19.2 percent) of chain coffee retailers locate in one of Melbourne's eleven largest suburban shopping centers compared to 127 of 4,347 (2.9 percent) independent retailers (Table 1).

Fourth, there is less heterogeneity in product offerings for coffee shops and cafes than in other industries such as discount retailing, which makes the definition of local markets more precise. For 2014-15, coffee sales contributed 51 percent of the revenue generated by coffee shops and cafes, food (e.g. sandwiches, eggs and toast, cookies) contributed 27.5 percent, and other beverages (e.g. milkshakes, tea, hot chocolate) contributed the remaining 21.5 percent (Gargano, 2014, p. 13). Our data include information on both coffee shops and cafes. Both types serve coffee drinks but cafes also emphasize their food offerings. The major chains operating in Melbourne (e.g. Gloria Jeans, McCafe, and Muffin Break) are coffee shops. The overwhelming majority of independent retailers self-identify as cafes (Table 1$)$.

\subsection{Data}

Annual editions of the White and Yellow Pages provide data on 4,768 cafes and coffee shops open between 1991 and 2010 in the Greater Melbourne area. ${ }^{4}$ We record the name and location for all firms listing themselves as either a "Cafe" or "Coffee shop" in the Yellow Pages. ${ }^{5}$ We match entries across years, accounting for variations in how they display their name and address. ${ }^{6}$ The first year that an establishment is listed in the directory is designated as the opening year. The last year a

\footnotetext{
${ }^{4}$ Our data likely underestimate the extent of entry because Yellow Pages listings are voluntary. Nevertheless, this bias is likely to be small as a basic listing in the Yellow Pages is free.

${ }^{5}$ To focus on competition in the market for coffee, we do not include firms identifying themselves as a "Restaurant." We supplement Yellow Page listing with White Pages listings for chains. Additionally, we collect entry years of McCafes through correspondence with McDonald's, because McCafes typically entered into existing McDonald's restaurants.

${ }^{6}$ Business names often vary from year to year; for example, the "Apricot Tree Coffee Lounge" (2007-2010) is listed as "Apricot Tree Cafe" in 2008. To account for name changes or misspellings, we adopt the following rule: if a unique name is present in listings for two businesses in the same location in consecutive years, the listings are treated as the same firm. Therefore, "Errol's Pantry \& Bakehouse" and "Errol's Cafe" are considered the same firm, whereas "Flynn's Cafe" and "Robin's Cafe" are considered different firms. Some establishments listed different addresses representing the same location, due to suburb name and street name changes or the use of varying address forms (for example, "Corner of Smith Street and Jones Avenue" in some years, "123 Jones Avenue" or "Alias Shopping Center" in others). We use street directories, Google Maps, and the continuity of telephone numbers to resolve these issues.
} 
firm is listed in the directory is the closing year. ${ }^{7}$ Although we focus on the twenty-year period 1991-2010, we collect these data back to 1976 so that no entry dates are left-censored.

Firm addresses are geocoded and assigned to local markets based on Statistical Area Level 2 (SA2) boundaries. SA2s are defined by the Australian Bureau of Statistics to "represent a community that interacts together socially and economically" and have populations ranging from 3,000 to 25,000 persons. SA2s were chosen as a market definition to incorporate demographic data between 1991 and 2010. Due to a change in the geography of census regions in 2011, SA2s are the smallest regions with consistent boundaries during our sample period. Nevertheless, SA2s are likely to reflect the extent of competition between establishments, which is primarily local. In the Greater Melbourne area, there are 256 SA2s that ever had coffee shops between 1976 and 2010, which have an average population of 14,447 in 2011 . We divide the single SA2 for Melbourne's Central Business District (CBD), which contains 12.1 percent of all coffee shops in our data, into 34 separate SA1s. Eleven large suburban shopping centers that span more than 70,000 square meters are also considered separate markets. ${ }^{8}$ Our final data set therefore contains 300 unique markets. A plot of independent and chain retailers in 2010 reveal that chains are fairly uniformly distributed across the Greater Melbourne area (Figure 1).

To account for changes in market characteristics, we incorporate data on household income, population, and employment. These data are drawn from five-year censuses from 1991, 1996, 2001, 2006, and 2011. ${ }^{9}$ Weekly household income data is available in various ranges: $\$ 1-39, \$ 40-79, \ldots$, $\$ 2,000$ or more. We combine these bands to construct two variables: the percentage of middle income households (earning between $\$ 1,000$ and $\$ 2,000$ per week), and the percentage of high income households (earning more than $\$ 2,000$ per week).

Exit rates (the proportion of stores that exit in a given year) decline during our sample period, which motivates the inclusion of annual fixed effects in our regressions. Between 1992 and 1999, annual exit rates fluctuate between 14.3 and 19.6 percent. ${ }^{10}$ Between 2000 and 2009, exit rates fluctuate between 14.0 and 8.8 percent. Lower exit rates between 2000 and 2009 are driven by a decline in the exit rates of cafes, which make up the majority of establishments in our data.

\footnotetext{
${ }^{7}$ If a firm with the same name and location is not listed in a particular year, but is listed in both earlier and later years, then it is assumed to be present in the industry during the "missing" year(s).

${ }^{8}$ The shopping centers are: Chadstone Shopping Centre, Westfield Fountain Gate, Highpoint Shopping Centre, Westfield Knox, Westfield Southland, Westfield Doncaster, Watergardens Town Centre, Northland Shopping Centre, Bayside Shopping Centre, Werribee Plaza, and Eastland Shopping Centre.

${ }^{9}$ For years between censuses, we interpolate linearly from the two closest censuses.

${ }^{10}$ The exit rate in 1991 is 28.6 percent, which coincides with a severe economic downturn in Australia. Between 1990 and 1991, the unemployment rate in Victoria increased from 7.4 to 10.4 percent.
} 
Between 1998 and 2009, the exit rate for cafes declined from 20.9 to 9.9 percent. There are no discernible trends in exit rates for coffee shops and chains.

\section{Model and Estimation}

\subsection{Baseline specification}

Our baseline specification for estimating the probability that coffee retailer $i$ of type $j$ in market $\ell$ exits in period $t$ is:

$$
\operatorname{Pr}\left(\text { exit }_{i j \ell t}\right)=\Lambda\left(\beta_{1 j} n_{\text {chains } \ell t}+\beta_{2 j} n_{\text {cafelt }}+\beta_{3 j} n_{\text {coffeelt }}+\beta_{4 j} X_{\ell t}+\beta_{5 j} z_{i t}+\xi_{\ell}+\omega_{t}\right)
$$

where $n_{j \ell t}$ is the number of competing stores of type $j \in\{$ chain, cafe, coffee $\}$ in market $\ell$ at time $t, X_{\ell t}$ is a vector of market characteristics, $z_{i t}$ is the age of store $i$ in time $t, \xi_{\ell}$ is a market fixed effect, and $\omega_{t}$ is a year fixed effect. An observation is an incumbent store, and a location is a SA2, shopping centre, or downtown SA1. Equation 1 is estimated separately for each type.

Our baseline specification for entry logit regressions is similar. The dependent variable is whether any new shops of type $j$ entered into market $\ell$ in year $t$ :

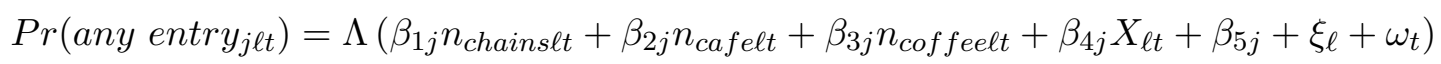

where all variables are defined as before. The only difference is the absence of store age, because the observational unit is a market instead of an incumbent store.

Because firms choose their locations based on market size, a naive regression with inadequate controls for market size or market characteristics would be biased. As desirable market characteristics are positively correlated with the number of competitors, firms would appear more likely to enter and less likely to exit a location with more competitors. We address this endogeneity concern by including observed market characteristics as well as market fixed effects to control for constant, unobserved characteristics affecting the profitability of a market. Observed characteristics, $X_{\ell t}$, are location-specific demographic variables: household income, population, and unemployment. Geographic market fixed effects, $\xi_{\ell}$ are possible given our long panel of 20 years. Annual fixed effects, $\omega_{t}$, control for economy-wide shocks that affect all coffee retailers, such as Australia's economic downturn in the early 1990s. A robustness check incorporates separate market fixed effects each five-year period of our panel. 
Location fixed effects are only identified for markets where exit is observed, because any large positive $\xi_{\ell}$ could rationalize the decision to never exit. Likewise, the use of year fixed effects only identifies $z_{t}$ in years when exit occurs. Though independent cafes exited in each year, no chain locations closed between 1992 and 1994, so those years are not used in estimating exit regressions for chains. Likewise, independent cafes never exited from 36 markets, so observations from these markets are not used. Nevertheless, there remain 255 separate markets for which we observe independent cafes exiting, and 48 separate markets in which we observe at least one chain exiting. In entry regressions, markets with no entry by a particular type are dropped, because any sufficiently negative $\xi_{\ell}$ would be consistent with no entrants finding the location profitable. There are 129 such markets where no chains enter and 15 markets where no independent cafes enter.

Under the assumption that $\xi_{\ell}$ and $X_{\ell t}$ adequately control for market characteristics, Equation 1 allows us to identify the causal impact of chain store entry on the exit probabilities of independent stores. The coefficient $\beta_{1 j}$ measures the change in the probability of store $i$ of type $j$ exiting when one additional chain store enters $i$ 's market. If $\beta_{1 j}>0$ then the entry of chain stores exerts competitive pressure on stores of type $j$ and increases the likelihood of exit. Similarly, $\beta_{1 j}$ in Equation 2 measures the impact of an additional chain store on the probability of a location adding at least one store of type $j$.

\subsection{Logit regressions as equilibrium policy function estimates}

Our baseline specification offers a transparent strategy for identifying the impact of chain store entry on the exit probabilities of independent stores. Furthermore, the logit estimates of our baseline specification also serve as estimates of the policy functions of a more sophisticated discrete time dynamic equilibrium model of entry and exit, which we describe here.

Agents in our model of entry and exit are defined by a location, $\ell$, and specialization, $j \in$ $\left\{\right.$ chain,cafe,coffee\}. ${ }^{11}$ The profits an incumbent shop of type $j$ make in period $t$ depend on the number of competitors in the location of each type, $n_{j \ell t}$, their location's observed and unobserved characteristics, $X_{\ell t}$ and $\xi_{\ell}$, the age of their shop, $z_{t}$, and overall city-wide conditions, $\omega_{t}$. Incumbent shops retain their specialization and location forever and decide only whether to permanently exit the industry. In every period and location, a set of potential entrants in each specialization

\footnotetext{
${ }^{11}$ Agents in this model, whether new entrants or incumbents, are single establishments. While this would seem inappropriate for chains that have a single management team that coordinates entry and exit decisions, note that the majority of chains in the Greater Melbourne area are franchises. Only three of the twelve chains are privately-owned: Brunetti, Coffee Bean and Tea Leaf, and Starbucks. The chains with the most locations (Gloria Jeans, McCafe, and Muffin Break) are franchise operations (Table 1).
} 
chooses between entering to become an incumbent in their location and specialization or remaining outside the market forever. At the beginning of the period, both incumbents and potential entrants independently draw a private, idiosyncratic, and completely transitory cost, $\epsilon_{1}$, and outside opportunity cost, $\epsilon_{0}$, from an identical, mean zero distribution. Incumbents remain if their expected future discounted profits are positive, that is if:

$$
E\left[\sum_{\tau=t}^{\infty} \beta^{\tau-t} \cdot \pi_{j}\left(n_{\text {chain } \ell}, n_{\text {cafel } \tau}, n_{\text {coffeel } \tau}, X_{\ell \tau}, \xi_{\ell}, z_{\tau}, \omega_{\tau}\right)\right]-\epsilon_{1}>\epsilon_{0} .
$$

Potentials entrants choose to become incumbents if:

$$
E\left[\sum_{\tau=t}^{\infty} \beta^{\tau-t} \cdot \pi_{j}\left(n_{\text {chains } \ell}, n_{c a f e \ell \tau}, n_{c o f f e e \ell}, X_{\ell \tau}, \xi_{\ell}, z_{\tau}, \omega_{\tau}\right)\right]-\kappa-\epsilon_{1}>\epsilon_{0}
$$

where $\kappa$ is the additional start-up cost that is common to all entrants and locations, and $\beta$ is a discount factor. Potential entrants only make their entry decision once. Those that enter become incumbents in the next period; those that remain out are replaced by a new set of entrants in the next period.

If agents use Markov strategies, then Equations 3 and 4 can be written recursively (Ericson and Pakes, 1995). Assuming the transition of location and store characteristics does not depend on variables from other locations, the Bellman equation for incumbent shops is:

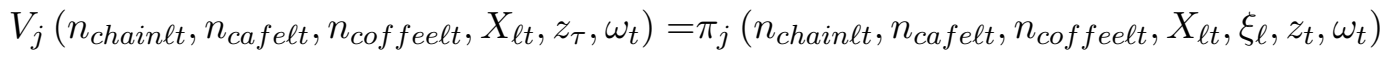

$$
\begin{aligned}
& +\beta E\left[V_{j}\left(n_{\text {chain } t+1}, n_{\text {cafelt }+1}, n_{\text {coffeelt }+1}, X_{\ell t+1}, \xi_{\ell}, z_{t+1}, \omega_{t+1}\right)\right] .
\end{aligned}
$$

Incumbents of type $j$ remain as long as $V_{j}\left(n_{\text {chainlt }}, n_{\text {cafelt }}, n_{\text {coffeelt }}, X_{\ell t}, z_{t}, \omega_{t}\right)>\epsilon_{1}-\epsilon_{0}$. A potential entrant of type $j$ opens shop if $\kappa$ and $z_{t}$ are such that $V_{j}\left(n_{\text {chain } t}, n_{\text {cafelt }}, n_{\text {coffeelt }}, X_{\ell t}, z_{t}, \omega_{t}\right)>$ $\kappa+\epsilon_{0}-\epsilon_{1}$.

Estimating the value function would require further assumptions on the functional form of value function and the transition functions. Our purpose is not to investigate intrinsically dynamic strategies, such as preemption (as in Igami and Yang, 2016) or predatory pricing (as in Snider, 2011), so recovering a value function is unnecessary here. Instead, our aim is to identify how chains affect the entry and exit decisions of independent shops, which is what the entry and exit policy functions provide. ${ }^{12}$ If the idiosyncratic cost, $\epsilon_{1}$, and value of the outside options, $\epsilon_{0}$,

\footnotetext{
${ }^{12}$ The question of how chains affect independents' profitability would require a period profit function recovered from
} 
are distributed according to the type I extreme value distribution, then the equilibrium exit policy function is recovered with the logit regressions described in Equation 1. Indeed, two-step estimators for dynamic models, such as Bajari, Benkard, and Levin (2007), use reduced form estimation in their first stage to recover policy functions.

The policy functions we estimate are specific to the observed equilibrium. A counterfactual equilibrium would, in principle, have different policy functions. Thus, although our results can be used to estimate the marginal effects at equilibrium of one more chain location, in general, estimated policy functions should not be used to simulate counterfactual experiments such as a ban on all chains. Here, however, very little interaction between chains and independents is apparent in the policy functions, which is consistent with chains and independents having little influence on each others' profits. If this is the case, any counterfactual equilibrium will produce policy functions similar to our estimates. The dynamic estimators currently developed (e.g. Aguirregabiria and Mira, 2007; Bajari, Benkard, and Levin, 2007) cannot accommodate market fixed effects; we prefer the simple logits because the endogeneity brought by unobserved market characteristics is most pressing in this setting. ${ }^{13}$

\section{Results}

\subsection{Chains versus independents}

We begin by analyzing the competitive pressure that coffee retailers exert on one another. Recall that there are two main organizational forms for such retailers - chains or independents. If coffee is a relatively homogeneous offering across outlets then chain entry would have the same impact on independents as independent entry. On the other hand, if there are differences in value to consumers contingent on organizational form, then we may see differences between organizational forms in their exit and entry patterns. If this were the case, this may also show evolution in organizational forms as chain growth, for instance, comes at the expense of independents.

Descriptive statistics suggest that growth in the number of chain stores operating in Melbourne after 2000 has not impeded the growth or dominance of independent operators (Figure 2). Between 2000 and 2010, the number of chain stores increased from 68 to 350 (or 415 percent). During the

value function estimation. Consumers, however, are concerned with firm profitability only for its effect on closure and entry activity that changes their choice set.

${ }^{13}$ Static models of entry or presence that use only a cross-section in equilibrium computation, such as Mazzeo (2002) or Seim (2006), are also not designed to include fixed effects. 
same period, the number of independent cafes increased from 988 to 1,739 (or 76 percent). Thus, overall density of coffee retailers has grown at the same time the share of independents has fallen. ${ }^{14}$ To determine whether these results are robust to controlling for market characteristics, we turn to logit regressions with market fixed effects.

Before presenting our main results, we first demonstrate the importance of adequately controlling for heterogeneity across markets when estimating exit probabilities. Without market demographics or fixed effects, each store increases the probability of another store exiting by 0.10 percentage points (Table 3, column 1, significant at 0.1 percent). Incorporating market fixed effects increases the estimated average effect almost five-fold, to 0.49 percent, demonstrating that unobserved market characteristics are important determinants of store failure (Table 3, column 3, significant at 0.1 percent). Incorporating demographic data and the age of the firm leaves the coefficient virtually unchanged: each competing cafe or coffee shop in a market increases the probability of exit by 0.48 percentage points (Table 3 , columns 5 , significant at 0.1 percent). This suggests that market fixed effects capture most of the variation in market characteristics.

Regression results by organizational form reveal that increased competition from chains does not drive out independent coffee shops. Each additional chain store has no effect on the exit probability of an independent cafe (Table 4, column 2). With the estimated exit probability function, removing all chains only lowers the mean exit probability of cafes from $14.88 \%$ to $14.84 \%$. Chain entry is actually negatively correlated with the exit of independent coffee shops, but the effect is not statistically significant (Table 4, column 3). The exit probability of chains is similarly unaffected by competition from independent cafes (Table 4, column 1)

Though competition from stores of a different type does not appear to exert any competitive pressure, competition from stores of the same type appears to significantly increase the probability of exit. Each additional chain store increases the probability of another chain store exiting by 2.5 percent (Table 4, column 1, significant at 0.3 percent). Each additional independent cafe increases the probability of cafe exit by 0.5 percent, and each additional independent coffee shop increases the annual exit probability of other independent coffee shops in its market by 17.0 percentage points (Table 4, columns 2 and 3, significant at 0.1 percent).

Market fixed effects capture average location characteristics or those characteristics that do not vary over time, such as the physical area or transportation infrastructure. However, some

\footnotetext{
${ }^{14}$ Independent operators identifying themselves as coffee shops (rather than cafes) represent a small share of the market. Between 1990 and 2010, the number increased from 45 to 55 .
} 
unobservable characteristics that influence entry and exit patterns are time-varying and may not be captured by changes in income and population. For example, the entry of coffee shops has been found to be associated with gentrification and lower crime rates (Smith, Scherer, Fugerio, 2011). To address this concern, we re-estimate our baseline exit equation with separate market fixed effects for every five-year interval. Estimated impacts of rival stores of the same organizational form are larger, which is consistent with time-varying unobserved market characteristics influencing exit patterns. Each additional chain coffee shop increases the likelihood of another chain coffee shop exiting by 7.2 percent compared to 2.5 percent in the baseline model (Table 5 , column 1 , significant at 2 percent). Each additional independent cafe increases the probability of another independent cafe exiting by 1.2 percent compared to 0.5 percent in the baseline model (Table 5 , column 2 , significant at 0.1 percent). However, most importantly, our main finding is unchanged: chain store entry continues to exhibit no significant effect on the likelihood of independent cafes or coffee shops exiting. In fact, an additional chain store cafe is estimated to lower the likelihood of an independent cafe from exiting by 0.6 percent (Table 5 , column 2, not significant at standard levels). ${ }^{15}$

Results are analogous for the probability of entry: retailers only exert competitive pressure on retailers of the same type. Each additional chain store in a neighborhood market decreases the probability of another chain store entering by 7.0 percentage points (Table 6, column 1, significant at 0.1 percent). Each additional independent cafe decreases the probability of independent cafe entry by 0.8 percentage points (Table 6 , column 2 , significant at 2 percent), and each additional independent coffee shop decreases the probability of coffee shops entering by 8.7 percentage points (Table 6, column 3, significant at 0.1 percent). Chain stores, again, do not have a significant effect on the location choices of independents. Each additional chain store in a market decreases the annual probability that any independent cafes enter that market by 1.3 percentage points (not significant) and that any independent coffee shops enters by 1.1 percentage points (not significant).

\footnotetext{
${ }^{15}$ In our data, 578 of 4,768 coffee retailers (12.1 percent) are located in Melbourne's CBD. To check that our results are not driven by entry and exit patterns in the CBD, we re-estimated the main exit specification after excluding observations from the CBD. Our findings are largely unchanged. Additional chain stores are again estimated to have a small and statistically insignificant effect on the exit probabilities of independent cafes and independent coffee shops. Stores of each type, again, are estimated to have a statistically significant effect on the exit probabilities of others of the same type. Each additional chain store increases the probability of chain store exit by 2.0 percent compared with 2.5 percent in the specification that includes the CBD. Each additional independent cafe increases the probability of cafe exit by 0.5 percent, the same as when the CBD is included. Each additional independent coffee shop is estimated to increase the probability of an independent coffee shop exiting by 16.6 percent compared to 17.5 percent using the full set of data.
} 


\subsection{Insight into the mechanism}

Our results, thus far, indicate that the locus of competition in coffee retailing is contingent on organizational form. The competitive pressure from chains is felt by other chain outlets while independents exert competitive pressure on one another. However, the results do not provide a mechanism as to why chains and independents appear to be in rather distinct markets given that their products appear to be similar.

One hypothesis is based on consumer information asymmetries. Consumers may not know the quality of coffee from a particular outlet or whether it fits with their tastes. Consequently, if they visit an outlet in their local neighborhood (or near their place of work), they will come to learn which outlet is preferred. Of course, neighborhoods also have consumers who are transient and so do not come to learn the same information. It is here where chains can fill the information gap. For instance, Luca (2016) in his study of restaurants and Yelp reviews found that the existence of such reviews assisted independents who had a strong quality offering but did not have an impact on chain performance. Here we examine whether we can distinguish different neighborhoods on the basis of the likely transience of their populations to see whether this impacts the competitive processes we have already examined. ${ }^{16}$

Tourists are likely to have less information than locals about the quality of coffee outlets as they have fewer opportunities to learn which outlets match their tastes. Additional data from two sources allow us to distinguish between the relative presence and preferences of tourists compared to locals. First, we obtained data on 175,564 photos of Melbourne that were uploaded to the photo and video hosting site Flickr. ${ }^{17}$ These data include the precise location of the photograph (based on geotags) and the time that the picture was taken. "Tourist" photos are taken from persons who took photos in Melbourne for less than a month (25.7 percent of photos). "Local" photos originate from persons who took pictures in Melbourne for a month or more. ${ }^{18}$

Poisson regressions provide some evidence that the number of chain stores operating within one of 1,953 SA1 boundaries is positively related to the share of photos uploaded by tourists. ${ }^{19}$

\footnotetext{
${ }^{16}$ Airports and hospitals are likely to cater to larger shares of transient consumers. Data on the identity of coffee outlets in 2010 suggest that chains were more likely to operate in these locations. Of the 9 coffee shops located at Melbourne's Tullamarine Airport, 7 were chains. Of the six Melbourne hospitals listing coffee shops, all contained the same chain (Hudson's).

${ }^{17}$ We are very grateful to Eric Fischer for sharing these data. A visual depiction of the the data for Melbourne and 135 other cities can be found at https://www.flickr.com/photos/walkingsf/sets/72157624209158632/with/ 4671519459/.

${ }^{18}$ We omit 106,356 photos for which it is unknown whether the photographer is a resident or a tourist because they did not take pictures anywhere for over a month.

${ }^{19} \mathrm{~A}$ poisson regression is appropriate here because the number of chains in a SA1 are count data. For the 1,953
} 
Controlling for demographic characteristics as well as the presence of a large shopping mall, a 10 percent increase in the share of tourists is associated with a 7.5 percent increase in the number of chain stores (Table 7 , column 3 , significant at 0.2 percent) ${ }^{20}$ The coefficient on tourist share is much smaller when we include an indicator variable to identify those 34 SA1s that comprise Melbourne's CBD (Table 7, column 4, not significant), as tourists and chains are both more prevalent in the CBD.

Data on 3,880 user reviews of 580 unique outlets (559 independent and 21 chain stores) in the Melbourne area from the website Yelp.com allow us to investigate whether non-locals might be more likely to visit, and review, chain stores compared to independent stores. Though non-local Yelp users might be able to infer the overall quality of an independent outlet using the website's reviews, compared to local users, they are less likely to know if it matches their particular tastes. This implies that non-locals may be more inclined to visit chains for which they have greater information. Of the 3,880 reviews, 70 reviews are for 21 unique chain stores. ${ }^{21}$ Non-locals, defined as those users residing outside Victoria, contributed 42.9 percent of chain store reviews and 37.3 percent of independent coffee shop reviews, which suggests that non-locals have a weak preference for chain stores. ${ }^{22}$

Data on the distribution of ratings also allow us to test whether there is greater variance in quality across independent stores, which would explain the growth in chain stores, particularly in those areas with larger shares of transient consumers. In these data, independent stores receive significantly higher ratings than chain stores. The average rating for independent stores is 3.8 (out of 5) compared to 3.2 for chain stores. The standard deviation of ratings, however, is only slightly higher for independent stores (0.84 compared to 0.81$)$. This is partly driven by selection: only those independent stores that are of high-enough quality to remain in business are represented in our data. Only 129 of 559 (23.1 percent) independent stores have average ratings of 3 or below. Therefore, our data likely underestimates the true variance in quality of independent cafes.

SA1s, there are no chains in 1,874 SA1s, 1 chain in $61 \mathrm{SA} 1 \mathrm{~s}, 2$ chains in $13 \mathrm{SA} 1 \mathrm{~s}$, and 3 or more in 9 SA1s.

${ }^{20}$ Only SA1 regions with photos uploads are included. Inclusion of the 478 SA1 regions without photo uploads requires assumptions about their tourist shares. Results are sensitive to those assumptions.

${ }^{21}$ The small share of chain store reviews is consistent with the finding that reviews have little impact on chains because uncertainty about quality is likely to be lower (Luca, 2016).

${ }^{22} \mathrm{~A}$ simple t test confirms that the difference in means, 5.6 percent, is not statistically significantly different from zero. 


\subsection{Old versus young firms}

Our dataset allows us to consider another aspect of the locus of competition: does entry come at the expense of young or old firms? A traditional hypothesis of creative destruction suggests that younger firms bring to market innovations that older firms cannot match. Consequently, entry would be expected to be at the expense of older firms. An alternative hypothesis is based on incumbency advantage perhaps due to brand, customer information on product quality or simply consumer habits. Under that hypothesis, growth in a market can lead to entry but the intensity of competitive pressure is felt between younger firms competing for new customers in the market. Here we examine the locus of competition with respect to firm age to see with which hypothesis (if any) the patterns of competition in the Melbourne coffee retailing market are consistent.

The data reveal that younger Melbourne independent coffee shops are more likely to exit than older independent establishments. This pattern generally holds even in markets where no new shops have entered. The presence of a new entrant enhances the importance of store tenure further. For an independent with average characteristics, each additional year of tenure is associated with a 0.5 percent decrease in its exit rate (Table 8, column 1, significant at 0.1 percent). Age is positively associated with survival both in markets where new stores enter and in markets where they do not, but younger shops are even more likely to exit where entry has occurred. There, an extra year of store tenure reduces exit rates by 0.6 percent, instead of by 0.2 percentage points as in markets with no new entry (Table 8, column 2).

Chain entry likewise causes young shops to exit more than older shops. In years where a new chain store opens in a market, an additional year of age reduces independent exit rates by 0.7 percent (Table 8, column 3, significant at 0.1 percent). In markets without new chains, older stores still exit less, but the effect is smaller: a year lowers exit probability by 0.5 percent (Table 8 , column 3 , significant at 0.1 percent).

Among chains themselves, exit is more likely with older rather than younger stores such that more recently opened locations are less likely to close. After controlling for neighborhood effects and demographics, an additional year of tenure increases the probability of closure by 0.4 percentage (Table 8, column 4, significant at 6 percent). Age is more a disadvantage in markets without a new entrant, again implying new entrants are more likely to drive younger establishments to exit (Table 8, column 5).

The tenure effects on exit and the response of those effects to new entry is consistent with 
reputation and established customer bases shielding old shops from entry. Customer loyalty and brand reputation may act more at the firm level than establishment level for chains, so their youngest locations are more protected.

\section{Conclusion}

This article has assessed the impact of chain stores on independent retailers in the Melbourne coffee market between 1991 and 2010. To control for the endogeneity of store location choices, we include market fixed effects, which is possible given the length of the panel. Simple panel logit regressions indicate that chain stores and independent retailers compete in different market segments. Chain stores have no discernible effect on the exit decisions of independent stores. However, each additional chain store increases the exit probability of another chain store by 2.5 percentage points, and each additional independent cafe increases the exit probability of another independent cafe by 0.5 percentage points. Results are robust to including separate market fixed effects for every five-year interval.

This analysis offers new insights into market structure and its determinants. The idea that at a local level, independents and chains may operate in somewhat distinct markets, sheds important light on the role of information, particularly information about product quality, on market competition. In this case, information about product quality can be transmitted (or not) based on organizational form. Thus, organizational form choice may not be secondary to product differentiation but may be an important source of it. This has implications as to how market competition is viewed for policy purposes including antitrust analysis that often evaluates large chain mergers with some weight placed on competitive pressures from independents in local areas. However, it may turn out that substitution possibilities between them are more limited in practice. 


\section{References}

[1] Aguirregabiria, Victor, and Pedro Mira. "Sequential Estimation of Dynamic Discrete Games." Econometrica, 2007, v. 75(1), pp. 1-53.

[2] Bajari, Patrick, C. Lanier Benkard, and Jonathan Levin. "Estimating Dynamic Models of Imperfect Competition." Econometrica, 2007, v. 75(5), pp. 1331-1370.

[3] Clark, Taylor. Starbucked. 2008, New York, NY: Little, Brown, and Company.

[4] Ericson, Richard and Ariel Pakes. "Markov-Perfect Industry Dynamics: A Framework for Empirical Work." Review of Economic Studies, 1995, v. 62(1), pp. 53-82,

[5] Gargano, Stephen. "Cafes and Coffee Shops in Australia." IBISWorld Industry Report H4511b, November 2014.

[6] Igami, Mitsuru, and Nathan Yang. "Unobserved Heterogeneity in Dynamic Games: Cannibalization and Preemptive Entry of Hamburger Chains in Canada." Quantitative Economics, 2016, v. $7(2)$, pp. $483-521$.

[7] Jellie, Dugald. "Lessons in Lattes." Sydney Morning Herald, 27 March 2007.

[8] Krugman, Paul R. Geography and trade. Cambridge, MA: MIT Press, 1991.

[9] Luca, Michael. "Reviews, Reputation, and Revenue: The Case of Yelp.Com." Harvard Business School NOM Unit Working Paper No. 12-016, 2016.

[10] Mazzeo, Michael. "Product Choice and Oligopoly Market Structure." RAND Journal of Economics, 2002, v. 33(2), pp. 1-22.

[11] Patterson, Paul G., Jane Scott, and Mark D. Uncles. "How the Local Competition Defeated a Global Brand: The Case of Starbucks." Australian Marketing Journal, 2010, v. 18(1), pp. 41-47.

[12] Seim, Katya. "An Empirical Model of Firm Entry With Endogenous Product-Type Choices." RAND Journal of Economics, 2006, v. 37(3), pp. 619-640.

[13] Smith, Chris, Mary Scherer, and Melissa Fugerio. "More Coffee, Less Crime? The Influence of Gentrification on Neighborhood Crime Rates in Chicago." City \& Community, 2011, v. 10(3), pp. $215-240$. 
[14] Snider, Conner. "Predatory Incentives and Predation Policy: The American Airlines Case." Mimeo., 2011. 
Table 1: Coffee retailers and locations

\begin{tabular}{lcrrrr}
\hline & & & Large & & \\
Type & Franchise & CBD & Mall & Other & Total \\
\hline Independent Cafe & & 519 & 123 & 3,554 & 4,196 \\
Independent Coffee Shop & & 7 & 4 & 140 & 151 \\
Chain & & & & & \\
$\quad$ BB's Cafe & Y & 4 & 10 & 16 & 30 \\
Bonbons & Y & 0 & 7 & 8 & 15 \\
Brunetti & & 1 & 0 & 5 & 6 \\
Coffee Bean and Tea Leaf & & 2 & 4 & 5 & 11 \\
Coffee Club & Y & 0 & 8 & 14 & 22 \\
Degani & Y & 7 & 4 & 21 & 32 \\
Gloria Jeans & Y & 10 & 21 & 48 & 79 \\
Hudson's & Y & 12 & 1 & 17 & 30 \\
Jamaica Blue & Y & 1 & 7 & 7 & 15 \\
McCafe & Y & 7 & 2 & 109 & 118 \\
Muffin Break & Y & 2 & 13 & 23 & 38 \\
Starbucks & & 6 & 4 & 15 & 25 \\
\hline Total & & 578 & 208 & 3,982 & 4,768 \\
\hline
\end{tabular}

Notes: Data on 4,768 cafes and coffee shops that were in business between 1991 and 2010 were hand collected from annual editions of the White Pages and Yellow Pages. Retailers self-identify as either a "Cafe" or "Coffee shop." CBD is Melbourne's Central Business District. Large Mall includes 11 large suburban shopping centres that span more than 70,000 square meters. 
Table 2: Summary Statistics of Market Characteristics

\begin{tabular}{lcccc}
\hline \hline \multicolumn{1}{c}{ Variable } & Mean & Std. Dev. & Min. & Max. \\
\hline Total cafes and coffee shops & 3.664 & 5.345 & 0 & 53 \\
Chain stores in market & 0.432 & 1.072 & 0 & 11 \\
Indep. cafes in market & 3.076 & 4.766 & 0 & 50 \\
Indep. coffee shops in market & 0.157 & 0.445 & 0 & 3 \\
Closures & 0.437 & 0.951 & 0 & 11 \\
Entrants & 0.716 & 1.307 & 0 & 16 \\
Any Entry & 0.379 & 0.485 & 0 & 1 \\
$\quad$ by chains & 0.059 & 0.235 & 0 & 1 \\
$\quad$ by inde cafes & 0.345 & 0.476 & 0 & 1 \\
$\quad$ by coffee shops & 0.015 & 0.122 & 0 & 1 \\
Neighborhood population (thousands) & 12.771 & 6.503 & 0 & 33.436 \\
Large Mall & 0.037 & 0.188 & 0 & 1 \\
Middle income households (\%) & 26.264 & 6.408 & 0 & 62.5 \\
High income households (\%) & 11.904 & 9.451 & 0 & 100 \\
Neighborhood unemployment rate $(\%)$ & 7.892 & 3.326 & 3.132 & 23.571 \\
\hline Markets $\times$ years & \multicolumn{4}{c}{$300 \times 20=6,000$} \\
\hline
\end{tabular}

Notes: Each observation is a market-year pair. Data on 4,768 cafes and coffee shops that were in business between 1991 and 2010 were hand collected from annual editions of the White Pages and Yellow Pages. Retailer self-identified as either a "Cafe" or "Coffee shop." CBD is Melbourne's Central Business District. Large Mall includes 11 large suburban shopping centres that span more than 70,000 square meters. Demographic data from the Australian Bureau of Statistics. 
Table 3: Logit-Incumbent exit

\begin{tabular}{|c|c|c|c|c|c|}
\hline & $(1)$ & $(2)$ & $(3)$ & $(4)$ & $(5)$ \\
\hline Competitors in market & $\begin{array}{c}0.0010^{* * *} \\
(0.0003)\end{array}$ & $\begin{array}{l}0.0007^{*} \\
(0.0003)\end{array}$ & $\begin{array}{c}0.0049^{* * *} \\
(0.0008)\end{array}$ & $\begin{array}{c}0.0053^{* * *} \\
(0.0009)\end{array}$ & $\begin{array}{c}0.0048^{* * *} \\
(0.0009)\end{array}$ \\
\hline $\begin{array}{l}\text { High income households } \\
\qquad(\% \text { earning }>\$ 2,000 / \text { wk })\end{array}$ & & $\begin{array}{c}0.0006 \\
(0.0004)\end{array}$ & & $\begin{array}{l}-0.0007 \\
(0.0012)\end{array}$ & $\begin{array}{l}-0.0011 \\
(0.0012)\end{array}$ \\
\hline $\begin{array}{l}\text { Middle income households } \\
\text { (\% earning } \$ 1,000 \text { to } \$ 2,000 / \mathrm{wk})\end{array}$ & & $\begin{array}{c}-0.0021^{* * *} \\
(0.0006)\end{array}$ & & $\begin{array}{l}-0.0020 \\
(0.0014)\end{array}$ & $\begin{array}{l}-0.0031^{*} \\
(0.0013)\end{array}$ \\
\hline Neighborhood unemployment rate & & $\begin{array}{l}-0.0010 \\
(0.0013)\end{array}$ & & $\begin{array}{c}0.0053 \\
(0.0029)\end{array}$ & \\
\hline $\begin{array}{l}\text { Neighborhood population } \\
\quad \text { (thousands) }\end{array}$ & & $\begin{array}{l}0.0014^{* *} \\
(0.0004)\end{array}$ & & $\begin{array}{c}0.0018 \\
(0.0014)\end{array}$ & $\begin{array}{c}0.0016 \\
(0.0014)\end{array}$ \\
\hline Store tenure & & & & & $\begin{array}{c}-0.0042^{* * *} \\
(0.0006)\end{array}$ \\
\hline Observations & 19841 & 19841 & 19522 & 19522 & 19509 \\
\hline Pseudo $R^{2}$ & 0.018 & 0.020 & 0.041 & 0.042 & 0.045 \\
\hline Log-likelihood & -7611.2 & -7599.4 & -7378.0 & -7371.1 & -7341.9 \\
\hline
\end{tabular}

Notes: Marginal effects reported. Standard errors in parentheses. ${ }^{*} p<0.05,{ }^{* *} p<0.01,{ }^{* * *} p<0.001$. Data on 4,768 cafes and coffee shops that were in business between 1991 and 2010 were hand collected from annual editions of the White and Yellow Pages. Markets are defined by Statistical Area Level 2 (SA2) boundaries. We divide Melbourne's Central Business District, which contains $12.1 \%$ of all coffee shops in our data, into 34 separate markets based on SA1 boundaries. Eleven large suburban shopping centres that span more than 70,000 square meters are also considered separate markets. Demographic data from the Australian Bureau of Statistics. 
Table 4: Logit-Incumbent exit by organizational form

\begin{tabular}{|c|c|c|c|}
\hline & $\begin{array}{c}(1) \\
\text { Chains }\end{array}$ & $\begin{array}{c}(2) \\
\text { Cafes }\end{array}$ & $\begin{array}{c}(3) \\
\text { Coffee }\end{array}$ \\
\hline Competing chain stores & $\begin{array}{l}0.025^{* *} \\
(0.008)\end{array}$ & $\begin{array}{c}0.000 \\
(0.004)\end{array}$ & $\begin{array}{l}-0.020 \\
(0.028)\end{array}$ \\
\hline Competing indep. cafes & $\begin{array}{l}-0.000 \\
(0.004)\end{array}$ & $\begin{array}{c}0.005^{* * *} \\
(0.001)\end{array}$ & $\begin{array}{l}-0.009 \\
(0.007)\end{array}$ \\
\hline Competing indep. coffee shops & $\begin{array}{c}0.021 \\
(0.021)\end{array}$ & $\begin{array}{c}0.005 \\
(0.007)\end{array}$ & $\begin{array}{c}0.170^{* * *} \\
(0.036)\end{array}$ \\
\hline $\begin{array}{l}\text { High income households } \\
\qquad(\% \text { earning }>\$ 2,000 / \mathrm{wk})\end{array}$ & $\begin{array}{l}-0.007 \\
(0.004)\end{array}$ & $\begin{array}{l}-0.002 \\
(0.001)\end{array}$ & $\begin{array}{r}-0.050^{* * *} \\
(0.014)\end{array}$ \\
\hline $\begin{array}{l}\text { Middle income households } \\
\text { (\% earning } \$ 1,000 \text { to } \$ 2,000 / \text { wk) }\end{array}$ & $\begin{array}{c}-0.010^{* * *} \\
(0.003)\end{array}$ & $\begin{array}{l}-0.003 \\
(0.002)\end{array}$ & $\begin{array}{l}-0.017 \\
(0.011)\end{array}$ \\
\hline $\begin{array}{l}\text { Neighborhood population } \\
\quad \text { (thousands) }\end{array}$ & $\begin{array}{c}0.003 \\
(0.005)\end{array}$ & $\begin{array}{c}0.001 \\
(0.002)\end{array}$ & $\begin{array}{l}-0.003 \\
(0.020)\end{array}$ \\
\hline Store tenure & $\begin{array}{l}0.004^{*} \\
(0.002)\end{array}$ & $\begin{array}{c}-0.005^{* * *} \\
(0.001)\end{array}$ & $\begin{array}{c}0.002 \\
(0.002)\end{array}$ \\
\hline Observations & 1189 & 16462 & 661 \\
\hline Pseudo $R^{2}$ & 0.202 & 0.044 & 0.230 \\
\hline
\end{tabular}

Notes: Marginal effects reported. Standard errors in parentheses. ${ }^{*} p<0.05,{ }^{* *} p<0.01,{ }^{* * *} p<0.001$. Data on 4,768 cafes and coffee shops that were in business between 1991 and 2010 were hand collected from annual editions of the White and Yellow Pages. Markets are defined by Statistical Area Level 2 (SA2) boundaries. We divide Melbourne's Central Business District, which contains $12.1 \%$ of all coffee shops in our data, into 34 separate markets based on SA1 boundaries. Eleven large suburban shopping centres that span more than 70,000 square meters are also considered separate markets. Demographic data from the Australian Bureau of Statistics. 
Table 5: Logit-Exit by type, including separate market fixed effects for each five-year interval

\begin{tabular}{lccc}
\hline \hline & $(1)$ & $(2)$ & $(3)$ \\
& Chains & Cafes & Coffee \\
\hline Competing chain stores & $0.072^{*}$ & -0.006 & -0.053 \\
& $(0.028)$ & $(0.008)$ & $(0.114)$ \\
Competing indep. cafes & -0.012 & $0.012^{* * *}$ & $-0.049^{*}$ \\
& $(0.015)$ & $(0.002)$ & $(0.022)$ \\
Competing indep. coffee shops & 0.119 & 0.008 & $0.522^{* * *}$ \\
& $(0.077)$ & $(0.013)$ & $(0.111)$ \\
High income households $(\%$ earning $>\$ 2,000 /$ wk) & $-0.069^{*}$ & -0.009 & $-0.166^{*}$ \\
& $(0.035)$ & $(0.006)$ & $(0.068)$ \\
Middle income households $(\%$ earning $\$ 1,000$ to $\$ 2,000 /$ wk) & $-0.028^{*}$ & 0.000 & -0.013 \\
& $(0.012)$ & $(0.005)$ & $(0.042)$ \\
Neighborhood population (thousands) & & & \\
& -0.026 & 0.002 & -0.229 \\
Store tenure & $(0.031)$ & $(0.012)$ & $(0.147)$ \\
\hline Observations & & & \\
Pseudo $R^{2}$ & 0.003 & $-0.005^{* * *}$ & -0.002 \\
\hline \hline
\end{tabular}

Notes: Marginal effects reported. Standard errors in parentheses. ${ }^{*} p<0.05,{ }^{* *} p<0.01,{ }^{* * *} p<0.001$. Data on 4,768 cafes and coffee shops that were in business between 1991 and 2010 were hand collected from annual editions of the White and Yellow Pages. Markets are defined by Statistical Area Level 2 (SA2) boundaries. We divide Melbourne's Central Business District, which contains $12.1 \%$ of all coffee shops in our data, into 34 separate markets based on SA1 boundaries. Eleven large suburban shopping centres that span more than 70,000 square meters are also considered separate markets. Demographic data from the Australian Bureau of Statistics. 
Table 6: Logit-New entry by organizational form

\begin{tabular}{lccc}
\hline \hline & $(1)$ & $(2)$ & $(3)$ \\
& Chains & Cafes & Coffee \\
\hline Chain stores in market & $-0.070^{* * *}$ & -0.013 & -0.011 \\
& $(0.007)$ & $(0.009)$ & $(0.011)$ \\
& & & \\
Indep. cafes in market & 0.002 & $-0.008^{*}$ & 0.006 \\
& $(0.003)$ & $(0.003)$ & $(0.003)$ \\
& & & \\
Indep. coffee shops in market & 0.005 & -0.015 & $-0.087^{* * *}$ \\
& $(0.019)$ & $(0.023)$ & $(0.018)$ \\
High income households & $0.011^{* * *}$ & 0.004 & -0.003 \\
$\quad(\%$ earning $>\$ 2,000 / \mathrm{wk})$ & $(0.003)$ & $(0.002)$ & $(0.003)$ \\
& & & \\
Middle income households & $0.007^{* *}$ & 0.005 & $-0.011^{* *}$ \\
$\quad(\%$ earning $\$ 1,000$ to $\$ 2,000 / \mathrm{wk})$ & $(0.002)$ & $(0.002)$ & $(0.004)$ \\
& & & \\
Neighborhood population & 0.001 & $0.005^{*}$ & 0.001 \\
$\quad($ thousands $)$ & $(0.002)$ & $(0.002)$ & $(0.005)$ \\
\hline Observations & 3249 & 5320 & 1216 \\
Pseudo $R^{2}$ & 0.264 & 0.283 & 0.153 \\
\hline \hline
\end{tabular}

Notes: Marginal effects reported. Standard errors in parentheses. ${ }^{*} p<0.05,{ }^{* *} p<0.01,{ }^{* * *} p<0.001$. The dependent variable, any entry $y_{j \ell}$, equals 1 if there is new entry by a store of type $j$ in market $\ell$ in year $t$, and zero otherwise. Data on 4,768 cafes and coffee shops that were in business between 1991 and 2010 were hand collected from annual editions of the White and Yellow Pages. Markets are defined by Statistical Area Level 2 (SA2) boundaries. We divide Melbourne's Central Business District, which contains $12.1 \%$ of all coffee shops in our data, into 34 separate markets based on SA1 boundaries. Eleven large suburban shopping centres that span more than 70,000 square meters are also considered separate markets. Demographic data from the Australian Bureau of Statistics. 
Table 7: Poisson-Chain store count in 2010

\begin{tabular}{|c|c|c|c|c|}
\hline & $(1)$ & $(2)$ & $(3)$ & $(4)$ \\
\hline Tourist share & $\begin{array}{l}0.496^{*} \\
(0.237)\end{array}$ & $\begin{array}{c}0.437 \\
(0.287)\end{array}$ & $\begin{array}{l}0.720^{* *} \\
(0.230)\end{array}$ & $\begin{array}{c}0.246 \\
(0.331)\end{array}$ \\
\hline $\begin{array}{l}\text { High income households } \\
\qquad(\% \text { earning }>\$ 2,000 / \text { wk })\end{array}$ & & $\begin{array}{c}0.032 \\
(0.022)\end{array}$ & $\begin{array}{l}0.036 \\
(0.020)\end{array}$ & $\begin{array}{c}0.054 \\
(0.029)\end{array}$ \\
\hline $\begin{array}{l}\text { Middle income households } \\
\text { (\% earning } \$ 1,000 \text { to } \$ 2,000 / \text { wk) }\end{array}$ & & $\begin{array}{l}0.133^{*} \\
(0.061)\end{array}$ & $\begin{array}{l}0.122^{* *} \\
(0.043)\end{array}$ & $\begin{array}{c}0.085 \\
(0.054)\end{array}$ \\
\hline Neighborhood unemployment rate & & $\begin{array}{c}0.294^{* * *} \\
(0.059)\end{array}$ & $\begin{array}{c}0.285^{* * *} \\
(0.060)\end{array}$ & $\begin{array}{c}0.132 \\
(0.089)\end{array}$ \\
\hline Neighborhood population (thousands) & & $\begin{array}{c}0.102^{* * *} \\
(0.027)\end{array}$ & $\begin{array}{c}0.084^{* * *} \\
(0.024)\end{array}$ & $\begin{array}{c}0.001 \\
(0.020)\end{array}$ \\
\hline Large mall & & & $\begin{array}{c}4.303^{* * *} \\
(0.519)\end{array}$ & $\begin{array}{c}5.142^{* * *} \\
(0.199)\end{array}$ \\
\hline CBD & & & & $\begin{array}{c}3.541^{* * *} \\
(0.409)\end{array}$ \\
\hline Constant & $\begin{array}{c}-2.791^{* * *} \\
(0.153)\end{array}$ & $\begin{array}{c}-10.601^{* * *} \\
(2.096)\end{array}$ & $\begin{array}{c}-10.260^{* * *} \\
(1.834)\end{array}$ & $\begin{array}{c}-7.991^{* *} \\
(2.498)\end{array}$ \\
\hline Observations & 1953 & 1953 & 1953 & 1953 \\
\hline Pseudo $R^{2}$ & 0.003 & 0.087 & 0.204 & 0.305 \\
\hline Log-likelihood & -535.729 & -490.566 & -427.822 & -373.193 \\
\hline
\end{tabular}

Notes: Standard errors in parentheses. ${ }^{*} p<0.05,{ }^{* *} p<0.01,{ }^{* * *} p<0.001$. Data on 350 chain coffee shops that were in business in 2010 were hand collected from annual editions of the White and Yellow Pages. 1,953 markets are defined by Statistical Area Level 1 (SA1) boundaries. Tourist share is the fraction of photos taken in a market by tourists that were uploaded to the photo and video hosting site Flickr. "Tourist" photos are pictures taken from people who took photos in Melbourne for less than a month (25.66 percent of photos). Otherwise, the photo is assumed to originate from a local (74.34 percent). Large mall is a dummy variable denoting the presence of a large shopping mall in the market. $C B D$ is a dummy indicating that the market is part of Melbourne's Central Business District. Demographic data from the Australian Bureau of Statistics. Data on 175,564 photos taken in Melbourne city area provided by Eric Fischer. 
Table 8: Logit-Exit for Independents, by store tenure

\begin{tabular}{|c|c|c|c|c|c|}
\hline & $\begin{array}{c}(1) \\
\text { Indes }\end{array}$ & $\begin{array}{c}(2) \\
\text { Indes }\end{array}$ & $\begin{array}{c}(3) \\
\text { Indes }\end{array}$ & $\begin{array}{c}(4) \\
\text { Chains }\end{array}$ & $\begin{array}{c}(5) \\
\text { Chains }\end{array}$ \\
\hline Competitors in market & $\begin{array}{c}0.005^{* * *} \\
(0.001)\end{array}$ & $\begin{array}{c}0.005^{* * *} \\
(0.001)\end{array}$ & $\begin{array}{c}0.005^{* * *} \\
(0.001)\end{array}$ & $\begin{array}{c}0.006 \\
(0.003)\end{array}$ & $\begin{array}{l}0.007^{*} \\
(0.004)\end{array}$ \\
\hline $\begin{array}{l}\text { High income households } \\
\qquad(\% \text { earning }>\$ 2,000 / \mathrm{wk})\end{array}$ & $\begin{array}{l}-0.001 \\
(0.001)\end{array}$ & $\begin{array}{l}-0.001 \\
(0.001)\end{array}$ & $\begin{array}{l}-0.001 \\
(0.001)\end{array}$ & $\begin{array}{l}-0.007 \\
(0.004)\end{array}$ & $\begin{array}{l}-0.006 \\
(0.004)\end{array}$ \\
\hline $\begin{array}{l}\text { Middle income households } \\
\quad(\% \text { earning } \$ 1,000 \text { to } \$ 2,000 / \mathrm{wk})\end{array}$ & $\begin{array}{l}-0.003 \\
(0.001)\end{array}$ & $\begin{array}{l}-0.003 \\
(0.001)\end{array}$ & $\begin{array}{l}-0.003 \\
(0.001)\end{array}$ & $\begin{array}{c}-0.009^{* *} \\
(0.003)\end{array}$ & $\begin{array}{c}-0.009^{* * *} \\
(0.003)\end{array}$ \\
\hline $\begin{array}{l}\text { Neighborhood population } \\
\quad \text { (thousands) }\end{array}$ & $\begin{array}{c}0.001 \\
(0.002)\end{array}$ & $\begin{array}{c}0.001 \\
(0.002)\end{array}$ & $\begin{array}{c}0.001 \\
(0.002)\end{array}$ & $\begin{array}{c}0.001 \\
(0.005)\end{array}$ & $\begin{array}{c}0.001 \\
(0.005)\end{array}$ \\
\hline Store tenure & $\begin{array}{c}-0.005^{* * *} \\
(0.001)\end{array}$ & & & $\begin{array}{c}0.004 \\
(0.002)\end{array}$ & \\
\hline Store tenure $\times$ no entry & & $\begin{array}{l}-0.002^{*} \\
(0.001)\end{array}$ & & & $\begin{array}{l}0.008^{* *} \\
(0.003)\end{array}$ \\
\hline Store tenure $\times$ any entry & & $\begin{array}{c}-0.006^{* * *} \\
(0.001)\end{array}$ & & & $\begin{array}{c}0.002 \\
(0.002)\end{array}$ \\
\hline Store tenure $\times$ no chain entry & & & $\begin{array}{c}-0.005^{* * *} \\
(0.001)\end{array}$ & & \\
\hline Store tenure $\times$ any chain entry & & & $\begin{array}{c}-0.007^{* * *} \\
(0.002)\end{array}$ & & \\
\hline Observations & 17351 & 17351 & 17351 & 1189 & 1189 \\
\hline Pseudo $R^{2}$ & 0.042 & 0.042 & 0.042 & 0.186 & 0.194 \\
\hline Log-likelihood & -6929.199 & -6924.355 & -6928.503 & -218.897 & -216.715 \\
\hline
\end{tabular}

Notes: Marginal effects reported. Standard errors in parentheses. ${ }^{*} p<0.05,{ }^{* *} p<0.01,{ }^{* * *} p<0.001$. Data on 4,768 cafes and coffee shops that were in business between 1991 and 2010 were hand collected from annual editions of the White and Yellow Pages. Markets are defined by Statistical Area Level 2 (SA2) boundaries. We divide Melbourne's Central Business District (CBD), which contains 12.1\% of all coffee shops in our data, into 34 separate markets based on SA1 boundaries. Eleven large suburban shopping centres that span more than 70,000 square meters are also considered separate markets. Demographic data from the Australian Bureau of Statistics. 


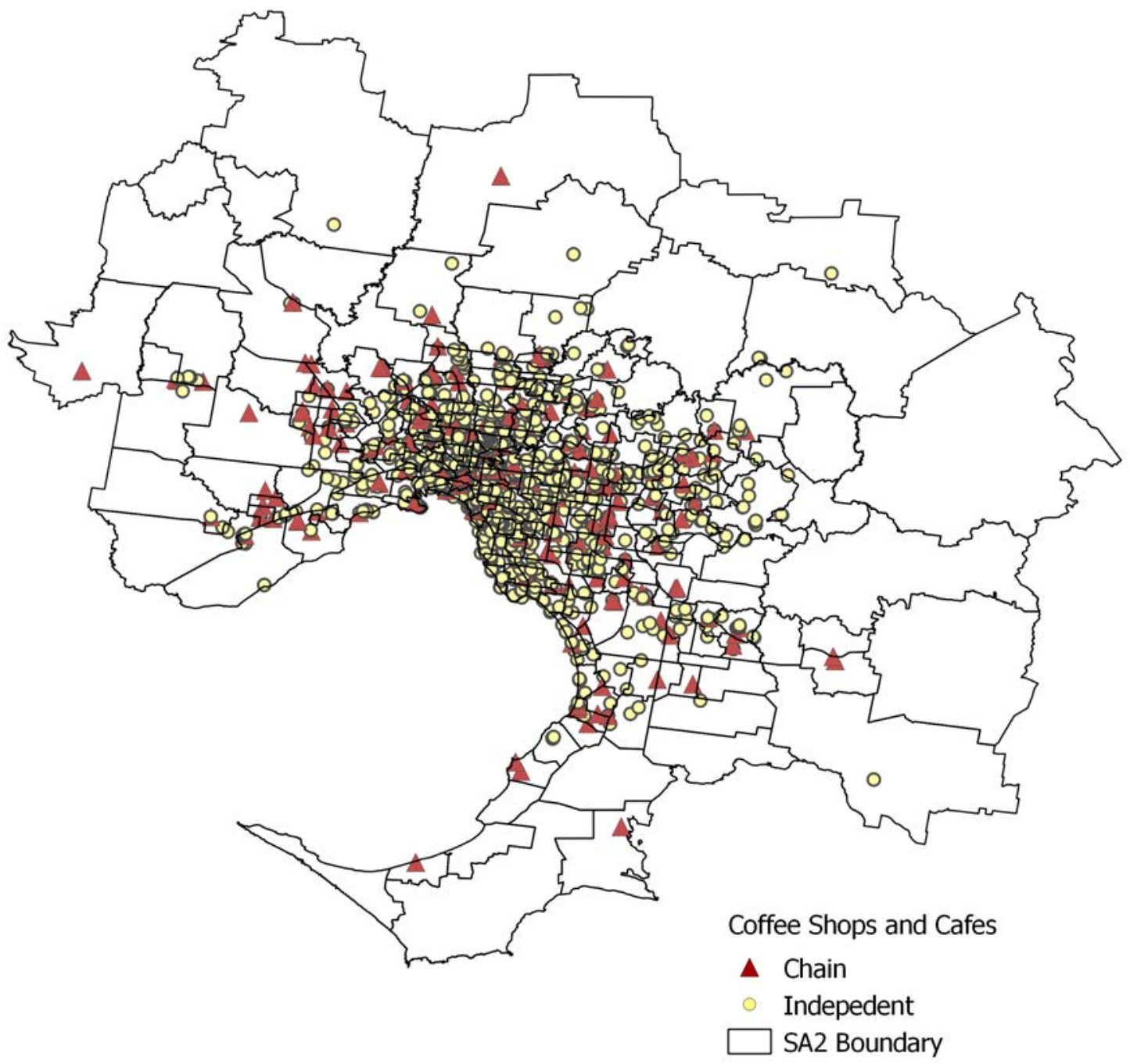

Figure 1: Coffee Shops in Greater Melbourne, 2010

Notes: Data on 4,196 independent cafes, 151 independent coffee shops, and 421 chain stores between 1991 and 2010 were hand collected from annual editions of the White and Yellow Pages. Markets are defined by Statistical Area Level 2 (SA2) boundaries. In the Greater Melbourne area, there are 256 SA2s that ever had coffee shops between 1976 and 2010, which have an average population of 14,447 in 2011. We divide Melbourne's Central Business District, which contains $12.1 \%$ of all coffee shops in our data, into 34 separate markets based on SA1 boundaries. 


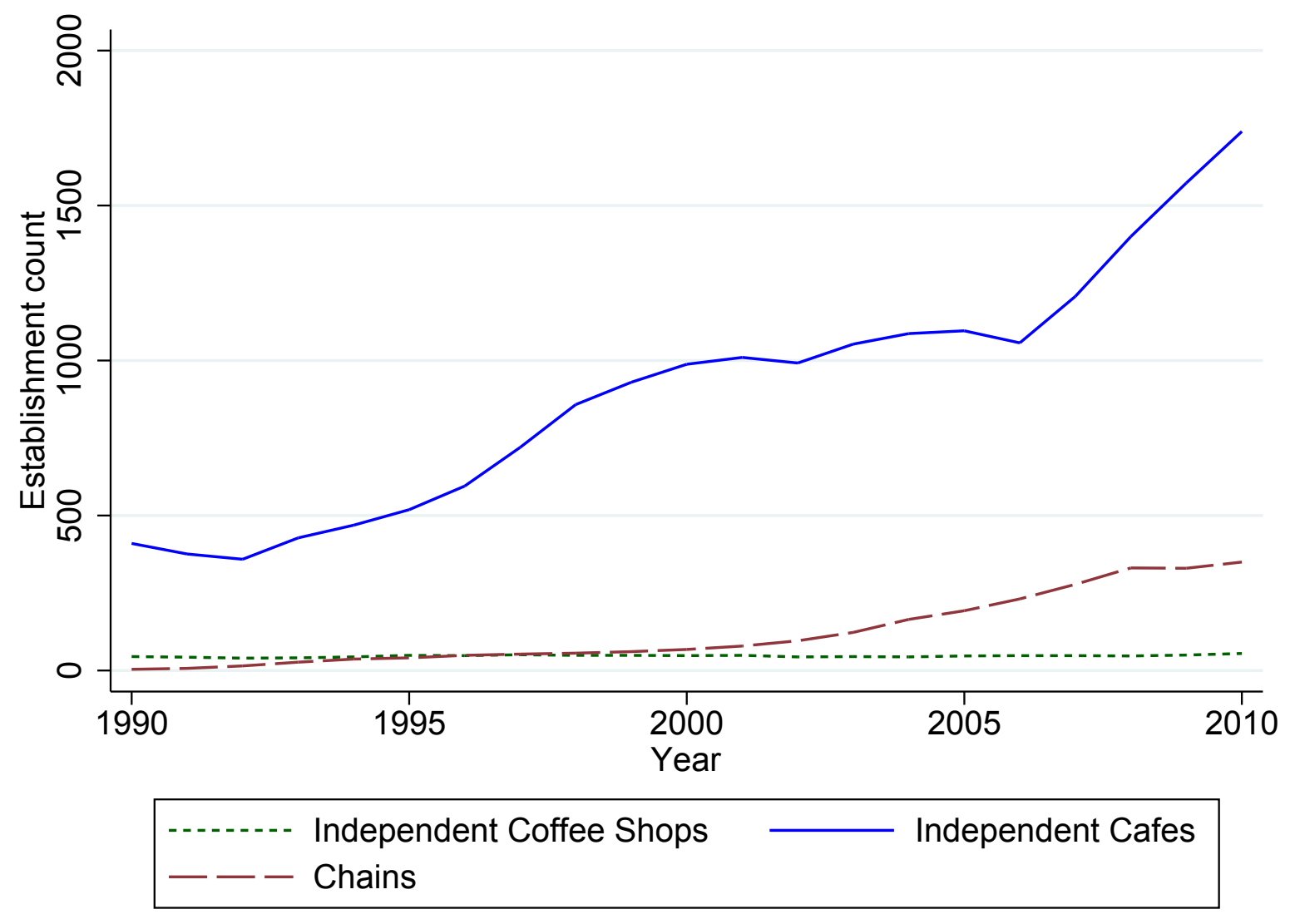

Figure 2: Establishment Counts in Greater Melbourne

Notes: Data on 4,196 independent cafes, 151 independent coffee shops, and 421 chain stores between 1991 and 2010 were hand collected from annual editions of the White and Yellow Pages. Retailers self-identify as either a "Cafe" or "Coffee shop." The chain stores are: BB's Cafe, Bonbons, Brunetti, Degani, Coffee Bean and Tea Leaf, Coffee Club, Jamaica Blue, Gloria Jeans, Hudson's, McCafe, Muffin Break, and Starbucks. 